\title{
RITME HARIAN KONSUMSI OKSIGEN INDUK IKAN MAS Cyprinus carpio DENGAN FOTOPERIODE KONTINYU 24 JAM
}

\author{
Vitas Atmadi Prakoso ${ }^{1)^{*}}$, Jun Hyung Ryu ${ }^{2)}$, dan Young Jin Chang ${ }^{3)}$ \\ ${ }^{1)}$ Balai Riset Perikanan Budidaya Air Tawar dan Penyuluhan Perikanan, Bogor \\ ${ }^{2)}$ Department of Marine Bio-materials and Aquaculture, Pukyong National University, \\ South Korea \\ ${ }^{3)}$ Institute of Review and Assessment on Fishery and Aquaculture, South Korea \\ e-mail: vitas.atmadi@gmail.com
}

\section{ABSTRACT \\ Diel Rhythm of Oxygen Consumption on Spawner of Common Carp Cyprinus carpio with Continuous 24-Hours Photoperiod}

\begin{abstract}
Some external factors could affect the metabolism rate of fish. One of them is photoperiod which related to the length of day and night in a day. Based on that correlation, the experiment was conducted to determine the effects of photoperiod manipulation to the rhythm of daily oxygen consumption on spawner of common carp Cyprinus carpio. The experimental fish (total length: $29.2 \pm 0.4 \mathrm{~cm}$, total weight: $1295.8 \pm 56.1 \mathrm{~g}$ ) was observed in respirometer which connected in a closed recirculation system. The study was conducted with three replications with one individual in each replication. The water temperature and closed recirculation system was maintained at $20.2 \pm 0.3^{\circ} \mathrm{C}$. The photoperiod was set to 24 hours light : 0 hours of dark by using fluorescent lamp which lit continuously. The results showed that during 24 hours observation at 24 hours light: 0 hours dark condition, spawner of common carp has an oxygen consumption range of $24.5-29.1 \mathrm{mg} \mathrm{O} / \mathrm{kg} / \mathrm{h}$ at $20^{\circ} \mathrm{C}$. The average value of the lowest oxygen consumption occurred at 02.00 and $17.00(24.5 \pm 1.9 \mathrm{mg} \mathrm{O} / \mathrm{kg} / \mathrm{h})$. Meanwhile, the highest oxygen consumption value was recorded at $06.00(29.1 \pm 1.7 \mathrm{mg} \mathrm{O} / \mathrm{kg} / \mathrm{h})$. Based on data of oxygen consumption obtained from this study, no significant difference found between oxygen consumption of spawner common carp during day and night with photoperiod manipulation. The activity and metabolism of spawner of common carp have changed with the change of photoperiod.
\end{abstract}

Keywords: Common carp, Cyprinus carpio, oxygen consumption, photoperiod.

\begin{abstract}
ABSTRAK
Beberapa faktor eksternal dapat mempengaruhi laju metabolisme pada ikan. Salah satu diantaranya adalah fotoperiode yang berkaitan dengan lamanya siang dan malam dalam satu hari. Berdasarkan korelasi tersebut, maka dilakukan penelitian untuk mengetahui pengaruh manipulasi fotoperiode terhadap ritme harian konsumsi oksigen pada induk ikan mas Cyprinus carpio. Ikan uji (panjang total 29,2 \pm 0,4 cm; bobot total 1295,8 $\pm 56,1 \mathrm{~g}$ ) diamati di dalam respirometer yang terhubung dalam sistem resirkulasi tertutup. Penelitian dilakukan dengan tiga ulangan dengan masing-masing jumlah induk ikan sebanyak satu ekor. Suhu air dan sistem resirkulasi tertutup diatur pada suhu 20,2 $\pm 0,3^{\circ} \mathrm{C}$. Fotoperiode diatur pada kondisi 24 jam terang : 0 jam gelap dengan menggunakan lampu fluorescent yang dinyalakan secara kontinyu. Hasil penelitian menunjukkan bahwa selama pengamatan 24 jam kondisi 24 jam terang : 0 jam gelap, induk ikan mas memiliki kisaran konsumsi oksigen sebesar 24,5 - 29,1 mg $\mathrm{O}_{2} / \mathrm{kg} / \mathrm{jam}$ di $20^{\circ} \mathrm{C}$. Nilai rata-rata konsumsi oksigen terendah terjadi pada jam 02.00 dan 17.00 , yaitu $24,5 \pm 1,9 \mathrm{mg}$

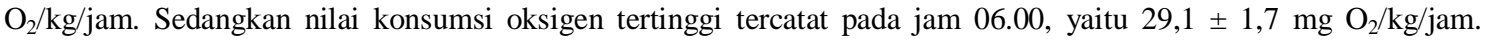
Berdasarkan data konsumsi oksigen yang diperoleh dari penelitian ini, tidak ditemukan adanya perbedaan nyata antara konsumsi oksigen induk ikan mas saat siang dan malam hari dengan adanya manipulasi fotoperiode. Aktivitas dan metabolisme induk ikan mas mengalami perubahan dengan adanya perubahan fotoperiode.
\end{abstract}

Kata kunci: Ikan mas, Cyprinus carpio, konsumsi oksigen, fotoperiode.

\section{PENDAHULUAN}

Konsumsi oksigen pada ikan menggambarkan status metabolisme basal dari ikan tersebut. Selain itu, konsumsi oksigen juga merupakan salah satu indikator fisiologis yang paling banyak diteliti dan menjadi indikator kesehatan ikan secara umum (White, Schimpf \& Cassey, 2013; Neelima, N.G. Rao, G.S. Rao \& J.C.S. Rao, 2016). Oksigen dalam keadaan molekuler sangat penting bagi banyak proses 
metabolisme yang sangat penting bagi kehidupan aerobik. Seperti semua organisme aerobik, tingkat metabolisme ikan dipengaruhi banyak faktor biotik dan abiotik (Martinez-Alvarez, Morales \& Sanz, 2005; Chabot, Steffensen \& Farrell., 2016; Rosewarne, Wilson \& Svendsen., 2016).

Kebanyakan jenis ikan lainnya, ikan mas merupakan regulator oksigen, mereka mempertahankan konsumsi oksigen pada tingkat konstan sepanjang gradien konsentrasi oksigen lingkungan sampai konsentrasi oksigen kritis tercapai, yang dapat menyebabkan penurunan konsumsi oksigen (Neelima et al., 2016). Hal serupa juga terjadi pada beberapa spesies ikan lainnya (Turker, 2011; Tirsgaard, Svendsen \& Steffensen., 2015; Prakoso, Ryu, Min, Gustiano \& Chang, 2016).

Perubahan harian dan musiman pada lingkungan pemeliharaan ikan akan mempengaruhi fungsi biologis dari ikan tersebut. Metabolisme ikan sebagian diatur oleh ritme harian (endogen) dan siklus diurnal (eksogen) (Parker, 1984). Dengan demikian pengetahuan tentang ritme konsumsi oksigen sehari-hari dan pengaruh kondisi lingkungan sangat penting bagi perikanan akuakultur secara ilmiah.

Saat ini penelitian tentang tingkat metabolisme ikan terfokus pada pengukuran ritme harian dalam aktivitas pemberian pakan. Akan tetapi, masih sedikit sekali informasi yang membahas mengenai ritme harian konsumsi oksigennya (Jobling, 1982; Guinea \& Fernandez, 1991; Sims, Davies, \& Bone., 1993).

Ikan mas Cyprinus carpio adalah salah satu ikan komersial yang populer di dunia. Beberapa studi tentang konsumsi oksigen ikan mas telah dilakukan pada berbagai macam ukuran (Ultsch, Ott \& Heisler, 1980; Hughes, Albers, Muster \& Gotz, 1983; Goenarso, Suripto \& Susanthi, 2009; Sulmartini, Chotimah, Tjahjaningsih, Widiyatno \& Triastuti, 2009; Yang \& Hu, 2014). Penelitian sebelumnya, mengukur tingkat konsumsi oksigen selama periode 12 jam atau kurang. Selain itu, pengaruh fotoperiode terhadap konsumsi oksigen pada ikan mas belum banyak dipelajari. Seperti yang diketahui, umumnya ikan mas hidup pada kondisi fotoperiode yang alami, dan dapat dikategorikan sebagai tipe diurnal yang aktif pada siang hari, sehingga konsumsi oksigennya lebih besar pada siang hari dibandingkan malam hari (Hughes et al., 1983). Berdasarkan beberapa penelitian terdahulu, perbedaan atau manipulasi fotoperiode memiliki pengaruh terhadap pola konsumsi oksigen pada ikan (Castanheira, Martins, Engrola \& Conceição, 2011; Chang, Jeong, Min, Neill \& Fontaine, 2005; Imsland et al., 1995), yang dapat berdampak terhadap aktivitas, pertumbuhan, dan juga reproduksi ikan (Imsland, Folkvord \& Stefansson, 1995; Liu et al., 2015; Tanaka, Mugiya \& Yamada., 1981). Penelitian ini dilakukan untuk mengetahui pola konsumsi oksigen harian induk ikan mas terhadap manipulasi lingkungan, berupa perubahan fotoperiode menjadi 24 jam terang : 0 jam gelap.

\section{BAHAN DAN METODE}

\section{Bahan dan Alat}

Ikan uji yang digunakan dalam penelitian yaitu induk ikan mas $C$. carpio dari jenis Israeli carp yang merupakan salah satu jenis ikan mas unggul yang tersedia di Korea Selatan. Ikan uji ini merupakan koleksi dari laboratorium tersebut yang dipelihara pada sistem resirkulasi indoor. Ikan uji memiliki kisaran panjang total 29,2 $\pm 0,4 \mathrm{~cm}$ dan bobot total $1295,8 \pm 56,1 \mathrm{~g}$. Peralatan yang digunakan yaitu respirometer ukuran 20 × $30 \times 20 \mathrm{~cm}$, lampu fluorescent, termometer, dan peralatan gelas lainnya.

\section{Metode}

Penelitian ini dilakukan di Fish Reproductive and Physiology Laboratory, Pukyong National University, Busan, Korea Selatan. Sebelum percobaan dimulai, ikan dipelihara dengan pemberian pakan komersial sebanyak 2\% dari bobot tubuhnya, dengan frekuensi pemberian pakan sebanyak dua kali sehari. Ikan uji dipuasakan selama 24 jam, menjelang percobaan pengukuran konsumsi oksigen untuk menghindari pengaruh pakan terhadap fluktuasi metabolisme ikan.

Ikan diletakkan di dalam respirometer berukuran $20 \times 30 \times 20 \mathrm{~cm}$ selama 3 jam sebelum percobaan untuk 
memperoleh kestabilan aktivitas ikan saat pengujian. Respirometer untuk pengukuran konsumsi oksigen terletak di dalam sistem resirkulasi tertutup. Pengukuran konsumsi oksigen yang dilakukan pada penelitian ini diadopsi dari Chang et al. (2005). Sementara itu, perhitungan frekuensi bernapas dilakukan berdasarkan metode pada penelitian Wares \& Igram (1979). Penelitian dilakukan dengan tiga ulangan dengan masing-masing jumlah induk ikan sebanyak satu ekor yang diletakkan dalam respirometer untuk pengujian. Suhu air dan sistem resirkulasi tertutup diatur pada suhu $20,2 \pm 0,3^{\circ} \mathrm{C}$. Fotoperiode diatur pada kondisi 24 jam terang: 0 jam gelap dengan menggunakan lampu fluorescent yang dinyalakan secara kontinyu.

\section{HASIL DAN PEMBAHASAN}

Metabolisme adalah proses fisiologis yang mencerminkan pengeluaran energi dari organisme hidup. Tingkat metabolisme ikan biasanya secara tidak langsung diukur melalui konsumsi oksigen. Pada induk ikan mas, konsumsi oksigen yang diukur setiap jam menunjukkan adanya fluktuasi. Nilai rata-rata konsumsi oksigen terendah terjadi pada jam 02.00 dan 17.00 , yaitu $24,5 \pm 1,9 \mathrm{mg} \mathrm{O} / \mathrm{kg} / \mathrm{jam}$. Sedangkan nilai konsumsi oksigen tertinggi tercatat pada jam 06.00, yaitu $29,1 \pm 1,7 \mathrm{mg}$ $\mathrm{O}_{2} / \mathrm{kg} / \mathrm{jam}$ (Gambar 1). Dalam penelitian ini, rata-rata konsumsi oksigen selama 24 jam yaitu $26,9 \pm 1,3 \mathrm{mg} \mathrm{O} / \mathrm{kg} / \mathrm{jam}$. Beamish \& Mookherjii (1964) melaporkan bahwa konsumsi oksigen ikan mencerminkan aktivitas ikan itu sendiri. Jika dihubungkan dengan penelitian ini, maka hasil pengamatan konsumsi oksigen pada induk ikan mas menggambarkan bahwa tidak terdapat kecenderungan penurunan aktivitas saat malam hari dengan adanya perlakuan penyinaran secara kontinyu selama 24 jam. Hasil pengamatan, rata-rata konsumsi oksigen dengan asumsi jumlah waktu siang dan malam hari yang alami menunjukkan bahwa tidak terdapat perbedaan nyata pada konsumsi oksigen induk ikan mas antara siang dan malam akibat paparan penyinaran yang kontinyu selama 24 jam, yaitu sebesar $27,2 \pm 1,2 \mathrm{mg} \mathrm{O} / \mathrm{kg} / \mathrm{jam}$ pada siang hari dan $26,3 \pm 1,4 \mathrm{mg} \mathrm{O} / \mathrm{kg} / \mathrm{jam}$ pada malam hari. Nilai rata-rata dari konsumsi oksigen tersebut menunjukkan bahwa dengan adanya pengaturan fotoperiode 24 jam periode terang : 0 periode gelap, tidak terjadi peningkatan konsumsi oksigen yang signifikan pada siang hari dibandingkan dengan malam hari (Tabel 1).

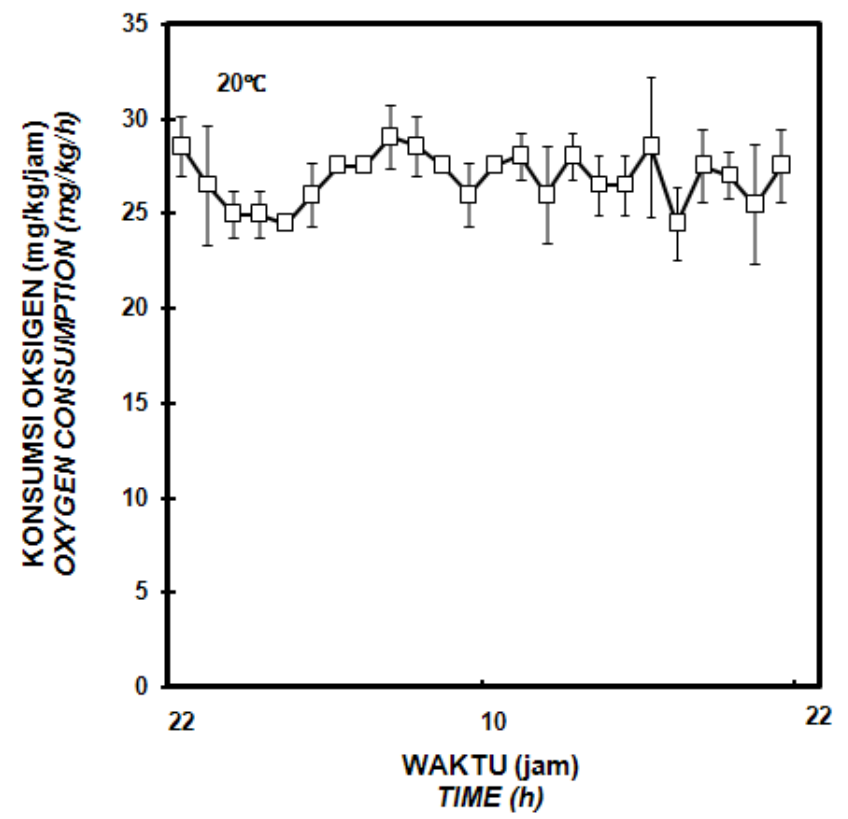

Gambar 1. Ritme Harian Konsumsi Oksigen Induk Ikan Mas Cyprinus carpio Selama 24 Jam pada Suhu Pemeliharaan $20^{\circ} \mathrm{C}$ 
Tabel 1. Rata-rata Konsumsi Oksigen ( $\left.\mathrm{mg} \mathrm{O}_{2} / \mathrm{kg} / \mathrm{jam}\right)$ dari Induk Ikan Mas Cyprinus carpio Saat Siang dan Malam Hari

\begin{tabular}{cccc}
\hline $\begin{array}{c}\text { Suhu }\left({ }^{\circ} \mathrm{C}\right) \\
\text { Temperature } \\
\left({ }^{\circ} \mathrm{C}\right)\end{array}$ & Waktu & Time & $\begin{array}{c}\text { Konsumsi oksigen } / \mathrm{kg} \\
\left(\mathrm{mg} \mathrm{O}_{2} / \mathrm{kg} / \mathrm{jam}\right)\end{array}$ \\
$\begin{array}{cccc}\text { Oxygen consumption } / \mathrm{kg} \\
\left(\mathrm{mg} \mathrm{O}_{2} / \mathrm{kg} / \mathrm{h}\right)\end{array}$ & $\begin{array}{c}\text { Konsumsi oksigen } / \text { ekor } \\
\left(\mathrm{mg} \mathrm{O}_{2} / \mathrm{kg} / \mathrm{ekor}\right) \\
\text { Oxygen consumption } / \text { fish } \\
\left(\mathrm{mg} \mathrm{O}_{2} / \mathrm{kg} / \text { fish }\right)\end{array}$ \\
\hline \multirow{2}{*}{20} & Siang & $27,2 \pm 1,2^{\mathrm{a}}$ & $35,3 \pm 2,0^{\mathrm{a}}$ \\
& Malam & $26,3 \pm 1,4^{\mathrm{a}}$ & $34,1 \pm 1,8^{\mathrm{a}}$ \\
\hline
\end{tabular}

Keterangan: Huruf superscript yang berbeda menunjukkan perbedaan yang signifikan antara siang dan malam ( $\mathrm{P}<0,05$, one-way ANOVA).

Tabel 2. Rata-rata Frekuensi Bernapas dan Konsumsi Oksigen dalam Sekali Bernapas dari Induk Ikan Mas Cyprinus carpio Saat Siang dan Malam Hari

\begin{tabular}{|c|c|c|c|}
\hline $\begin{array}{c}\text { Suhu }\left({ }^{\circ} \mathrm{C}\right) \\
\text { Temperature } \\
\left({ }^{\circ} \mathrm{C}\right)\end{array}$ & $\begin{array}{l}\text { Waktu } \\
\text { Time }\end{array}$ & $\begin{array}{c}\text { Frekuensi bernapas } \\
\text { (kali) } \\
\text { Breath frequency } \\
\text { (times) }\end{array}$ & $\begin{array}{l}\text { Konsumsi oksigen dalam sekali } \\
\text { bernapas }\left(\mathrm{mg} \mathrm{O}_{2} / \mathrm{kg}\right) \\
\text { Oxygen consumption per breath } \\
\left(\mathrm{mg} \mathrm{O}_{2} / \mathrm{kg}\right)\end{array}$ \\
\hline \multirow{2}{*}{20} & Siang & $90,3 \pm 3,1^{\mathrm{a}}$ & $0,00503 \pm 0,0002^{b}$ \\
\hline & Malam & $85,7 \pm 2,1^{\mathrm{a}}$ & $0,00512 \pm 0,0001^{\mathrm{a}}$ \\
\hline
\end{tabular}

Keterangan: Huruf yang berbeda menunjukkan perbedaan yang signifikan antara siang dan malam $(\mathrm{P}<0,05$, one-way ANOVA).

Dalam penelitian ini, diketahui konsumsi oksigen harian dari induk ikan mas berada pada kisaran 24,5 - 29,1 mg $\mathrm{O}_{2} / \mathrm{kg} / \mathrm{jam}$ pada suhu $20^{\circ} \mathrm{C}$. Metabolisme induk ikan mas pada siang hari dibanding malam hari tidak berbeda nyata pada penelitian ini. Pada umumnya, spesies ikan termasuk ikan mas memiliki perbedaan tingkat metabolisme antara siang dan malam hari tergantung dari spesies dan waktu aktif ikan tersebut. Beberapa spesies yang telah diteliti tingkat metabolismenya lebih tinggi saat siang hari karena merupakan tipe diurnal (Lim, Jeong, Han, Lee \& Chang., 2004; Biswas, Kazushige \& Takii, 2010; Oh, Park \& Kim., 2010). Sementara itu, ikan tipe nokturnal lebih aktif pada malam hari, sehingga tingkat metabolismenya lebih tinggi saat malam hari (Byun et al., 2008; Liu, Sakurai, Munehara \& Shimazaki, 1997; Sims et al., 1993).

Berdasarkan hasil studi ini, fotoperiode memiliki dampak pada ritme konsumsi oksigen dari induk ikan mas. Hal itu juga terkait dengan tingkah laku dan aktivitas ikan mas, seperti yang terlihat pada hasil yang menunjukkan metabolisme yang cenderung stabil tanpa adanya perbedaan signifikan pada siang maupun malam hari. Menurut Liu et al. (1997), tingkat aktivitas yang lebih tinggi dalam kondisi terang ataupun gelap merupakan konsekuensi dari pengaturan jam internal (indigenous cycle) yang dikendalikan secara eksternal. Pengaruh dari manipulasi fotoperiode terhadap aktivitas dan konsumsi oksigen ini juga dilaporkan oleh hasil penelitian sebelumnya pada beberapa jenis ikan (Castanheira et al., 2011; Chang et al., 2005; Imsland et al., 1995; Jeong, Kim, Min \& Chang, 2007) yang juga menyatakan bahwa perubahan fotoperiode berpengaruh terhadap konsumsi oksigen pada ikan.

Sama halnya dengan pengamatan konsumsi oksigen, pengamatan frekuensi pernapasan juga menunjukkan dampak yang serupa pada ritme konsumsi oksigen dari induk ikan mas akibat penyinaran kontinyu selama 24 jam (Tabel 2). Frekuensi bernapas induk ikan mas tidak berbeda nyata antara siang dan malam $(\mathrm{P}<0,05)$. Sementara itu, nilai rata-rata konsumsi oksigen dalam sekali bernapas pada induk ikan mas saat 
malam hari lebih tinggi dibandingkan saat siang hari $(\mathrm{P}>0,05)$.

Berdasarkan hasil pengukuran, nilai frekuensi bernapas dari induk ikan mas pada suhu pemeliharaan $20^{\circ} \mathrm{C}$ tidak berbeda nyata saat siang dan malam hari. Perubahan fotoperiode diduga merupakan faktor eksternal yang mempengaruhi hasil tersebut, karena umumnya ikan mas lebih aktif saat siang hari, sehingga dapat diasumsikan konsumsi oksigen dan frekuensi bernapasnya pada kondisi normal akan lebih tinggi pada siang hari. Pola yang ditemukan pada pengamatan ini juga serupa dengan penelitian sebelumnya pada spesies lainnya yang diberi perlakuan penyinaran 24 jam terang : 0 jam gelap (Imsland et al., 1995; Chang et al., 2005).

Beberapa penelitian pada sejumlah spesies ikan telah menunjukkan adanya ketergantungan terhadap siklus pencahayaan dalam kehidupannya (Boeuf \& Le Bail, 1999). Adanya manipulasi fotoperiode dapat berpengaruh positif terhadap pertumbuhan (Thorarensen \& Clarke, 1989; Cerqueira, Chatain, Lavens, Jaspers \& Ollevier, 1991; Kashyap, Chandra, Pathak, Awasthi \& Serajuddin., 2015) dan reproduksi (Hansen, Karlsen, Taranger, Hemre, Holm \& Kjesbu, 2001; Kissil, Lupatsch, Elizur \& Zohar, 2001; Fiszbein, Canepa, Vazquez, Maggese \& Pandolfi, 2010). Namun, pendekatan ini mungkin tidak berlaku umum untuk semua spesies. Beberapa jenis ikan tidak memiliki respon positif terhadap perubahan tersebut, sedangkan spesies lain membutuhkan waktu yang lama sebelum mengekspresikan pertumbuhan yang lebih baik (Boeuf \& Le Bail, 1999; Almazan-Rueda, Helmond, Verreth \& Schrama., 2005).

\section{KESIMPULAN}

Dari hasil penelitian ini, induk ikan mas memiliki kisaran konsumsi oksigen sebesar 24,5 - 29,1 $\mathrm{mg} \mathrm{O} / \mathrm{kg} / \mathrm{jam}$ di $20^{\circ} \mathrm{C}$ dengan perlakuan fotoperiode 24 jam terang : 0 jam gelap. Hal tersebut dapat dilihat dari tidak ditemukannya perbedaan nyata antara konsumsi oksigen induk ikan mas saat siang dan malam hari.

\section{UCAPAN TERIMAKASIH}

Penulis mengucapkan terimakasih kepada Kitae Kim atas kontribusinya selama penelitian berlangsung, serta kepada KOICA dan Pukyong National University atas fasilitas yang diberikan selama penelitian.

\section{DAFTAR PUSTAKA}

Almazan-Rueda, P., Helmond, A.T.M.V, Verreth, J.A.J. \& Schrama, J.W. (2005). Photoperiod affects growth, behaviour and stress variables in Clarias gariepinus. Journal of Fish Biology, 67, 1029-1039.

Beamish, F.W.H. \& Mookherjii, P.S. (1964). Respiration of fishes with special emphasis on standard oxygen consumption. II. Influence of weight and temperature on respiration of goldfish, Carassius auratus L. Canadian Journal of Zoology, 42, 161-175.

Biswas, A., Kazushige, I. \& Takii, K. (2010). Feeding interval and photoperiod influence the growth performance of striped knifejaw, Oplegnathus fasciatus. Aquaculture Research, 41, 517-523.

Boeuf, G. \& Le Bail, P. Y. (1999). Does light have an influence on fish growth?. Aquaculture, 177, 129-152.

Byun, S.G., Jeong, M.H., Lee, J.H., Lee, B.I., Ku, H.D., Park, S.U., Kim, Y.C. \& Chang, Y.J. (2008). Diel rhythm of oxygen consumption of the starry flounder Platichthys stellatus by water temperature. Journal of Korean Fisheries Society, 41, 113-118.

Castanheira, M.F., Martins, C.I.M., Engrola, S. \& Conceição, L.E.C. (2011). Daily oxygen consumption rhythms of Senegalese sole Solea senegalensis (Kaup, 1858) juveniles. Journal of Experimental Marine Biology and Ecology, 407, 1-5.

Cerqueira,V.R, Chatain, B., Lavens, P., Jaspers, E. \& Ollevier, F. (1991). 
Photoperiodic effects on the growth and feeding rhythm of European seabass, Dicentrarchus labrax, larvae in intensive rearing. Larvi'91, Special Publication European Aquaculture Society, 15, 304-306.

Chabot, D., Steffensen, J.F. \& Farrell, A.P. (2016). The determination of standard metabolic rate in fishes. Journal of Fish Biology, 88, 81-121.

Chang, Y.J., Jeong, M.H., Min, B.H., Neill, W.H. \& Fontaine, L.P. (2005). Effect of photoperiod, temperature, and fish size on oxygen consumption in the black porgy Acanthopagrus schlegelii. Journal of Fish Science and Technology, 8, 142-150.

Fiszbein, A., Canepa, M., Vazquez, G.R., Maggese, C. \& Pandolfi, M. (2010). Photoperiodic modulation of reproductive physiology and behaviour in the cichlid fish Cichlasoma dimerus. Physiology \& Behavior, 99, 425-432.

Goenarso, D., Suripto \& Susanthi, K.I. (2009). Konsumsi oksigen, kadar $\mathrm{Hb}$ darah, dan pertumbuhan ikan mas Cyprinus carpio, diberi pakan campuran ampas kelapa. Jurnal Matematika dan Sains, 8 No.(2), 51-56.

Guinea, J. \& Fernandez, F. (1991). The effect of SDA, temperature and daily rhythms on the energy metabolism of the mullet. Aquaculture, 97, 353-364.

Hansen, T., Karlsen, O., Taranger, G.L., Hemre, G.I., Holm, J.C. \& Kjesbu, O.S. (2001). Growth, gonadal development and spawning time of Atlantic cod (Gadus morhua) reared under different photoperiods. Aquaculture, 203, 51-67.

Hughes, G.M., Albers, C., Muster, D. \& Gotz, K.H. (1983). Respiration of the carp, Cyprinus carpio L., at 10 and $20^{\circ} \mathrm{C}$ and the effects of hypoxia. Journal of Fish Biology, 22, 613-628.

Imsland, A.K., Folkvord, A. \& Stefansson, S.O. (1995). Growth, oxygen consumption and activity of juvenile turbot (Scophthalmus maximus L.) reared under different temperatures and photoperiods. Netherlands Journal of Sea Research, 34, 149-159.

Jeong, M.H., Kim, Y.S., Min, B.H. \& Chang, Y.J. (2007). Effect of fish number in respiratory chamber on routine oxygen consumption of black porgy Acanthopagrus schlegelii reared in seawater or freshwater. Journal of Aquaculture, 20, 121-126.

Jobling, M. (1982). A study of some factors affecting rates of oxygen consumption of plaice, Pleuronectes platessa L. Journal of Fish Biology, 20, 501-516.

Kashyap, A., Chandra Pathak, B., Awasthi, M. \& Serajuddin, M. (2015). Effect of different photoperiods on the growth and survival of juvenile of Indian major carp, Catla catla. Iranian Journal of Fisheries Sciences, 14 No.(4), 946-955.

Kissil, G.W., Lupatsch, I., Elizur, A. \& Zohar, Y. (2001). Long photoperiod delayed spawning and increased somatic growth in gilthead seabream (Sparus aurata). Aquaculture, 200, 363-379.

Lim, H.K., Jeong, M.H., Han, H.K., Lee, J.H. \& Chang, Y.J. (2004). Oxygen consumption of hybrid stripped bass (Morone chrysops $\bigcirc \times$ M. saxatilis $\widehat{O}$ ) exposed to different temperature, salinity and photoperiod. Journal of Aquaculture, 17, 258-261.

Liu, H., Sakurai, Y., Munehara, H. \& Shimazaki, K. (1997). Diel rhythms of oxygen consumption and activity level of juvenile flounder Paralichthys olivaceus. Fisheries Science, 63 No.(5), 655-658.

Liu, Y. Li, X., Xu, G.F., Bai, S.Y., Zhang, Y.Q., Gu, W. \& Mou, Z.B. (2015). Effect of photoperiod manipulation on the growth performance of juvenile lenok, Brachymystax lenok (Pallas, 1773). Journal of Applied Ichthyology, $31,120-124$.

Martínez-Alvarez, R.M., Morales, A.E. \& Sanz, A. (2005). Antioxidant defenses in fish: Biotic and abiotic factors. 
Reviews in Fish Biology and Fisheries, $15,75-88$.

Neelima, P., Rao, N.G., Rao, G.S. \& Rao, J.C.S. (2016). A study on oxygen consumption in a freshwater fish Cyprinus carpio exposed to lethal and sublethal concentrations of cypermethrin $(25 \% \mathrm{Ec})$. International Journal of Current Microbiology and Applied Sciences, 5 No.(4), 338-348.

Oh, S.Y., Park, H.S. \& Kim, C.K. (2010). Effect of water temperature and photoperiod on the oxygen consumption rate of juvenile Pacific cod, Gadus macrocephalus. Ocean and Polar Research, 32, 229-236.

Parker, N.C. (1984). Chronobiologic approach to aquaculture. Transactions of the American Fisheries Society, 113, 545-552.

Prakoso, V.A., Ryu, J.H., Min, B.H., Gustiano, R. \& Chang, Y.J. (2016). Oxygen consumption of rockbream Oplegnathus fasciatus in different salinity levels and temperature degrees. Berita Biologi, 15 No.(2), 167-173.

Rosewarne, P. J., Wilson, J.M. \& Svendsen, J.C. (2016). Measuring maximum and standard metabolic rates using intermittent-flow respirometry: a student laboratory investigation of aerobic metabolic scope and environmental hypoxia in aquatic breathers. Journal of Fish Biology, 88, 265-283.

Sims, D.W., Davies, S.J. \& Bone, Q. (1993). On the diel rhythms in metabolism and activity of post-hatching lesser spotted dogfish, Scyliorhinus. Journal of Fish Biology, 43, 749-754.

Sulmartini, L., Chotimah, D.N., Tjahjaningsih, W., Widiyatno, T.V. \& Triastuti, J. (2009). Respon daya cerna dan respirasi benih ikan mas (Cyprinus carpio) pasca transportasi dengan menggunakan daun bandotan (Ageratum conyzoides) sebagai bahan antimetabolik. Jurnal Ilmiah Perikanan dan Kelautan, 1 No.(1), 79-86.
Tanaka, K., Mugiya, Y. \& Yamada, J. (1981). Effects of photoperiod and feeding on daily growth patterns in otoliths of juvenile Tilapia nilotica. Fishery Bulletin, 79 No.(3), 459-466.

Thorarensen, H. \& Clarke, W.C. (1989). Smoltification induced by a 'skeleton' photoperiod in underyearling coho salmon Oncorhynchus kisutch. Fish Physiology and Biochemistry, 6, 11-18.

Tirsgaard, B., Svendsen, J. C. \& Steffensen, J. F. (2015). Effects of temperature on specific dynamic action in Atlantic cod Gadus morhua. Fish Physiology and Biochemistry, 41, 41-50.

Turker, H. (2011). The effect of water temperature on standard and routine metabolic rate in two different sizes of Nile tilapia. Kafkas Universitesi Veteriner Fakultesi Dergisi, 17, 575580.

Ultsch, G.R., Ott, M.E. \& Heisler, N. (1980). Standard metabolic rate, critical oxygen tension, and aerobic scope for spontaneous activity of trout (Salmo gairdneri) and carp (Cyprinus carpio) in acidified water. Comparative Biochemistry and Physiol ogy, 67, 329-335.

Wares, W.D. \& Igram, R. (1979). Oxygen consumption in the fathead minnow (Pimephales promelas Rafinesque), effects of weight, temperature, group size, oxygen level, and opercular movement rate as a function of temperature. Comparative Biochemistry and Physiology, 62, 351-356.

White, C.R., Schimpf, N.G. \& Cassey, P. (2013). The repeatability of metabolic rate declines with time. Journal of Experimental Biology, 216, 1763-1765.

Yang, J.L. \& Hu, T.J. (2014). Oxygen consumption and histochemical studies of common carp (Cyprinus carpio) exposed to various levels of gallium. Environmental Science An Indian Journal, 9 No.(3), 113-117. 